\title{
In the Newborn Hippocampus, Neurotrophin-Dependent Survival Requires Spontaneous Activity and Integrin Signaling
}

\author{
Sachiko Murase, ${ }^{1}$ David F. Owens, ${ }^{1}$ and Ronald D. McKay ${ }^{1,2}$ \\ ${ }^{1}$ Laboratory of Molecular Biology, National Institute of Neurological Disorders and Stroke, National Institutes of Health, Bethesda, Maryland 20892, \\ and 2 Lieber Institute for Brain Development, Baltimore, Maryland 21205
}

The nervous system develops through a program that first produces neurons in excess and then eliminates as many as half in a specific period of early postnatal life. Neurotrophins are widely thought to regulate neuronal survival, but this role has not been clearly defined in the CNS. Here we show that neurotrophins promote survival of young neurons by promoting spontaneous activity. Survival of hippocampal neurons in neonatal rat requires spontaneous activity that depends on the excitatory action of GABA. Neurotrophins facilitate recruitment of cultured neurons into active networks, and it is this activity, combined with integrin receptor signaling, that controls neuronal survival. In vivo, neurotrophins require integrin signaling to control neuron number. These data are the first to link the early excitatory action of GABA to the developmental death period and to assign an essential role for activity in neurotrophin-mediated survival that establishes appropriate networks.

\section{Introduction}

The importance of cell death in the development of the nervous system was revealed by pioneering work in the periphery showing that the size of the target (muscle) regulates the number of motor neurons. Nerve growth factor (NGF) was shown to control neuronal differentiation and survival in the PNS (Levi-Montalcini, 1987). These findings led to the influential idea that neurons are produced in excess, and that an activity-dependent competition for a limited supply of factors regulates neuron numbers. NGF forms a gene family with BDNF, neurotrophin-3 (NT3), and neurotrophin-4/5 (Barde, 1994; Bibel and Barde, 2000). However, in contrast to dramatic effects observed in the PNS, deleting the genes that encode neurotrophins or their receptors produces only minor effects on neuron number in the CNS (Jones et al., 1994; Minichiello and Klein, 1996; Alcántara et al., 1997; Rauskolb et al., 2010). As a consequence, no clear model has been developed to explain the survival of CNS neurons.

The hippocampus is widely studied because it plays an important role in memory formation (Cooke and Bliss, 2006). As in the other regions of CNS, death of hippocampal neurons occurs during the first postnatal week (Gould et al., 1991; Ferrer et al., 1994).

\footnotetext{
Received Jan. 12, 2011; revised Feb. 18, 2011; accepted March 4, 2011.

Author contributions: S.M., D.F.O., and R.D.M. designed research; S.M. and D.F.O. performed research; S.M. and D.F.O. analyzed data; S.M. and R.D.M. wrote the paper.

This research was supported by the Intramural Research Program of the National Institutes of Health, National Institute of Neurological Disorders and Stroke. We thank Drs. Antonella Antignani and Richard Youle for providing LFn-BCl-XL and PA, Drs. Joby Joseph and Mark Stopfer for advice on statistics and electrophysiological recording, and Drs. Arek Szklarczyk, Steve W. Poser, and Peter H. Maughan for the culture preparation. We also thank Drs. Moses Chao, Michael Sendtner, and Mu-Ming Poo for helpful advice on the manuscript.

Correspondence should be addressed to Ronald D. McKay, Lieber Institute for Brain Development, 855 North Wolfe Street, Baltimore, MD 21205. E-mail: ronaldmckay@mac.com.

DOI:10.1523/JNEUROSCI.0202-11.2011

Copyright $\odot 2011$ the authors $\quad 0270-6474 / 11 / 317791-10 \$ 15.00 / 0$
}

The neonatal hippocampus displays spontaneous synchronous activity mediated by depolarizing GABA, and this activity is thought to be important for the maturation of functional networks (Ben-Ari et al., 1997). However, whether or how such neonatal activity is linked to neuronal survival has not been tested.

Neurotrophins activate signaling pathways through the tropomyosin receptor kinase (Trk), and retrograde transport of the signaling endosome containing internalized Trk with the ligand is thought to control neuronal survival (Zweifel et al., 2005). However, neurons receive multiple extracellular survival signals. Integrins, which consist of heterodimers ( $\alpha$ and $\beta$ ) and interact with extracellular matrix, regulate various cell functions including survival (Hynes, 2002). Integrins play critical roles in the survival of developing and adult hippocampal neurons (Gary et al., 2003; Wakselman et al., 2008), as well as in the migration of neurons (Stanco et al., 2009) and maturation of synapses (Chavis and Westbrook, 2001). It remains unclear whether and how integrin signals are integrated with other extracellular cues and activity to control the number of neurons during the period of developmental neuronal death.

Here we show that GABA-mediated spontaneous activity regulates neuronal death in the neonatal hippocampus. In vitro, neuron number is reduced during a brief period when GABAdependent calcium responses develop in the neurons that preferentially survive. Specifically during this period, neurotrophins regulate neuron numbers indirectly by promoting this GABAmediated spontaneous activity. Neurotrophins transiently activate Trk receptors to promote survival through the sustained activation of the serine-threonine kinase Akt. This sustained activation of Akt requires both neuronal activity and integrin signaling. Acute pharmacological manipulations in vivo support a 
central role for integrins in neurotrophin-mediated survival of neonatal hippocampal neurons. These data define neuronal activity and integrin signaling as the direct mediators of neurotrophin-activated survival mechanisms. Our findings have implications for understanding the development of hippocampal networks.

\section{Materials and Methods}

Reagents. DL-2-Amino-5-phosphonovaleric acid (APV), bicuculline, tetrodotoxin (TTX), fluorouridine (FUDR), apotransferrin, putrescin, sodium selenite, progesterone, corticosterone, triiodothyronine, insulin, and echistatin were purchased from Sigma-Aldrich. LY294002 [2-(4morpholinyl)-8-phenyl-4 H-1-benzopyran-4-one] and bromodeoxyuridine (BrdU) were purchased from Roche. Recombinant human (rh) BDNF and rhNT3 were purchased from R\&D Systems. Modified MEM, GlutaMAX, and penicillin/streptomycin were purchased from Invitrogen.

Antibodies. Antibodies were used with the following dilutions: monoclonal mouse anti-MAP2 (Sigma-Aldrich), 1:500; polyclonal rabbit antiGABA, anti-c-cas3 (anti-cleaved caspase 3) (Cell Signaling Technology), 1:500; polyclonal goat anti-TrkB, anti-TrkC (R\&D Systems), 1:40 (concentration for function blocking recommended by the manufacturer); monoclonal rat anti-BrdU (Accurate Chemical and Scientific), 1:200; monoclonal mouse anti-NeuN (Millipore); polyclonal rabbit antiphospho Thr-308 Akt, anti-phospho Ser-473 Akt for Western blot, and immunohistochemistry, anti-phospho Tyr-490 TrkA/Tyr-516 TrkB (Cell Signaling Technology), 1:200; function-blocking hamster antiintegrin $\beta 1$ and mouse anti-integrin $\beta 3$ (BD Biosciences), 1:20; Alexa 488-conjugated goat anti-mouse IgG and Alexa 546-conjugated goat anti-rabbit IgG, 1:100; HRP-conjugated goat anti-rabbit IgG (Invitrogen), 1:2000.

Cell cultures. Culture was prepared as described previously (Murase and McKay, 2006). Hippocampi from embryonic day 18 Sprague Dawley rat embryos were used for both astrocyte (plated at a density of 80,000 cells $/ \mathrm{ml}$ ) and neuron (density, 200,000 cells/ml) cultures. Neurons were cultured in neuron medium (modified MEM containing $2 \mathrm{~mm}$ GlutaMAX, penicillin/streptomycin, $200 \mathrm{mg} / \mathrm{L}$ apotransferrin, $0.5 \mathrm{~mm}$ putrescin, $30 \mathrm{~nm}$ sodium selenite, $40 \mathrm{~nm}$ progesterone, $40 \mathrm{ng} / \mathrm{ml}$ corticosterone, $20 \mathrm{ng} / \mathrm{ml}$ triiodothyronine, $25 \mu \mathrm{g} / \mathrm{ml}$ insulin and FUDR). One-third of the medium was exchanged every 3-4 d.

$B c l-X L$ expression. A nontoxic derivative of anthrax toxin was used to deliver Bcl-XL peptide into the cytosolic compartment of cultured neurons (Liu et al., 2001). The first 254 residues of anthrax lethal factor (LFn) fused with Bcl-XL and protective antigen (PA) were a gift from Dr. Richard J. Youle (National Institute of Neurological Disorders and Stroke, National Institutes of Health, Bethesda, MD). Treatment was performed between the fifth day in vitro (DIV5) and DIV7 with either LFn-Bcl-XL $(50 \mu \mathrm{g} / \mathrm{ml})$ and PA $(40 \mu \mathrm{g} / \mathrm{ml})$, or BSA $(50 \mu \mathrm{g} / \mathrm{ml})$ and PA $(40 \mu \mathrm{g} / \mathrm{ml})$ as a control.

Transfection. Using Lipofectamine 2000 (Invitrogen), cotransfection with $1.6 \mu \mathrm{g} / \mathrm{ml}$ pEGFPC1 vector (Clontech) and $/$ or $8 \mu \mathrm{g} / \mathrm{ml}$ activated Akt1/pUSE vector (Millipore) per culture was performed for $1.5 \mathrm{~h}, 1 \mathrm{~d}$ before the experiments.

Immunocytochemistry. Cultures were fixed with $4 \%$ paraformaldehyde, permeabilized in $0.5 \%$ Triton X-100, and blocked with 5\% normal goat serum (NGS) (Vector Laboratories).

Rat neonatal brains were fixed with $4 \%$ paraformaldehyde followed by $20 \%$ sucrose at $4^{\circ} \mathrm{C}$. Coronal cryostat sections, $16 \mu \mathrm{m}$ thick, were blocked with $4 \%$ NGS in PBS with $0.1 \%$ Triton X-100. Antibodies were diluted in $4 \%$ NGS. Every fourth sequential section was used for immunohistochemistry.

Cell quantification. The fluorescent images were obtained with a Zeiss 510 confocal microscope running laser scanning microscopy using a $25 \times$ objective lens. Because the densities of neurons on the edge of coverslips were higher than in other regions, images were taken from the following 5 fields: one from the center of the coverslip, two vertically, and two horizontally $400-3000 \mu \mathrm{m}$ from the center. Numbers represent mean \pm SEM.
Each coverslip is defined as an individual culture. All the results were obtained from multiple cultures. All the analyses were performed blind.

Analyses of hippocampal sections were performed using NIH ImageJ. Every fourth sequential section was stained for c-cas 3 analyses. Identification of individual cells was confirmed by DAPI $\left(4^{\prime}, 6^{\prime}\right.$-diamidino-2phenylindole dihydrochloride) staining (to visualize nuclei), and cell type was determined by NeuN staining. Partly due to dimensional changes in the location of the hippocampus during development, the total numbers of sections from rostral to caudal ends of hippocampus were $\sim 160$ throughout development [postnatal day $1(\mathrm{P} 1)-\mathrm{P} 10$ ] despite the increase in total volume of hippocampus. Although the c-cas3 immunostaining produced a relatively high background, distinctive positive signals from apoptotic cells could be detected reliably using the threshold function in ImageJ.

$B r d U$. For experiments using BrdU, cultures were treated with BDNF and NT3 $(10 \mathrm{ng} / \mathrm{ml})$ or a vehicle control $(0.1 \%$ BSA in PBS) at DIV4, pulsed with BrdU $1 \mu \mathrm{M}$ at DIV5, and fixed at DIV6. Cells were fixed in $4 \mathrm{~N}$ $\mathrm{HCl}$ in distilled $\mathrm{H}_{2} \mathrm{O}$ for 10 min at room temperature, and blocked with $10 \%$ NGS and $0.3 \%$ Triton X-100 in PBS for $1 \mathrm{~h}$ at room temperature before immunostaining.

Western blot. Western blot was performed as described previously (Murase and McKay, 2006).

In vivo injection. In vivo injection to $\mathrm{CA} 1$ was described previously (Cunningham and McKay, 1993). Briefly, Sprague Dawley rat pups (P2) of either sex were anesthetized by hypothermia (in ice for $5 \mathrm{~min}$ ) before the surgery. The anesthetized animal was placed on ice in a stereotaxic instrument. The stereotaxic coordinates from bregma are as follows: anteroposterior, +1.5 ; mediolateral, \pm 1.8 ; ventrodorsal, $-1.8 \mathrm{~mm}$. Reagents $(0.3 \mu \mathrm{l})$ were delivered at a rate of $0.1 \mu \mathrm{l} / \mathrm{min}$ using a Hamilton syringe with a LASI needle attached to a pump. Concentrations of reagents were as follows: anti- $\beta 1$ antibody, $0.5 \mathrm{mg} / \mathrm{ml}$; BDNF, $50 \mu \mathrm{g} / \mathrm{ml}$; TTX, $30 \mu \mathrm{m}$; bicuculline, $1 \mathrm{~mm}$. PBS was used as control. The incision was closed using a 5-0 suture. Animals were allowed to recover at $37^{\circ} \mathrm{C}$ for $1-2 \mathrm{~h}$.

Calcium imaging. The cultures were incubated with $2 \mu \mathrm{M}$ Fluo-4 AM (Invitrogen) for $15 \mathrm{~min}$. The images were obtained with a Zeiss Axiovert $135 \mathrm{TV}$ microscope equipped with a $25 \times$ objective lens. The cultures were imaged in HEPES-buffered saline (HBS) (containing, in mM: 110 $\mathrm{NaCl}, 5.4 \mathrm{KCl}, 1.8 \mathrm{CaCl}_{2}, 0.8 \mathrm{MgCl}_{2}, 10$ D-glucose, 10 HEPES- $\mathrm{NaOH}$, $\mathrm{pH} 7.4,290 \mathrm{mOsm}$ ) at $37^{\circ} \mathrm{C}$ using a CCD camera (Hamamatsu) at 3 $\mathrm{Hz}$ for $30 \mathrm{~s}$.

Electrophysiological recording. Whole-cell recording was performed with pipettes containing the following internal solution (in $\mathrm{mm}$ ): 136 K-gluconate, $10 \mathrm{KCl}, 5 \mathrm{NaCl}, 0.1$ EGTA, $0.3 \mathrm{Na}-\mathrm{GTP}, 1 \mathrm{Mg}$-ATP, 5 phosphocreatine, 10 HEPES, pH 7.2. The resistance of the pipettes was in the range of 1-10 M $\Omega$. Signals were amplified with a DC amplifier (model 440, Brownlee Precision). Electrophysiological recordings were synchronized with calcium images $(20 \mathrm{~Hz})$ by custom software written in Labview (National Instruments). During recording sessions, neuron cultures were perfused with $\mathrm{HBS}$ at a flow rate of $2.5 \mathrm{ml} / \mathrm{min} ; 2 \mathrm{ml}$ of 10 $\mathrm{ng} / \mathrm{ml}$ BDNF was applied followed by HBS for $5 \mathrm{~min}$.

Detection of apoptotic neurons with annexin $V$. The cultures were imaged in Neurobasal medium supplemented with B27 containing $5 \mu \mathrm{l} / \mathrm{ml}$ PE annexin V (BD Biosciences) with a Zeiss Axiovert 135TV microscope equipped with a $10 \times$ objective lens. The cultures were incubated at $37^{\circ} \mathrm{C}$ with $10 \% \mathrm{CO}_{2}$ using a live cell chamber (Zeiss). Phase and fluorescent images were taken every hour for $3 \mathrm{~d}$.

Statistical analyses. Statistical significance between two groups was determined with a two-tailed paired Student's $t$ test. For multiple groups, statistical comparisons were made by ANOVA followed by individual group tests corrected for multiple comparisons.

\section{Results}

\section{Spontaneous neuronal activity and death}

As have others (Ferrer et al., 1994), we observed apoptosis during the first postnatal week in the rat hippocampus. The numbers of $\mathrm{NeuN}^{+}$neurons in CA1 and CA3 cell layers decreased by $30-$ 

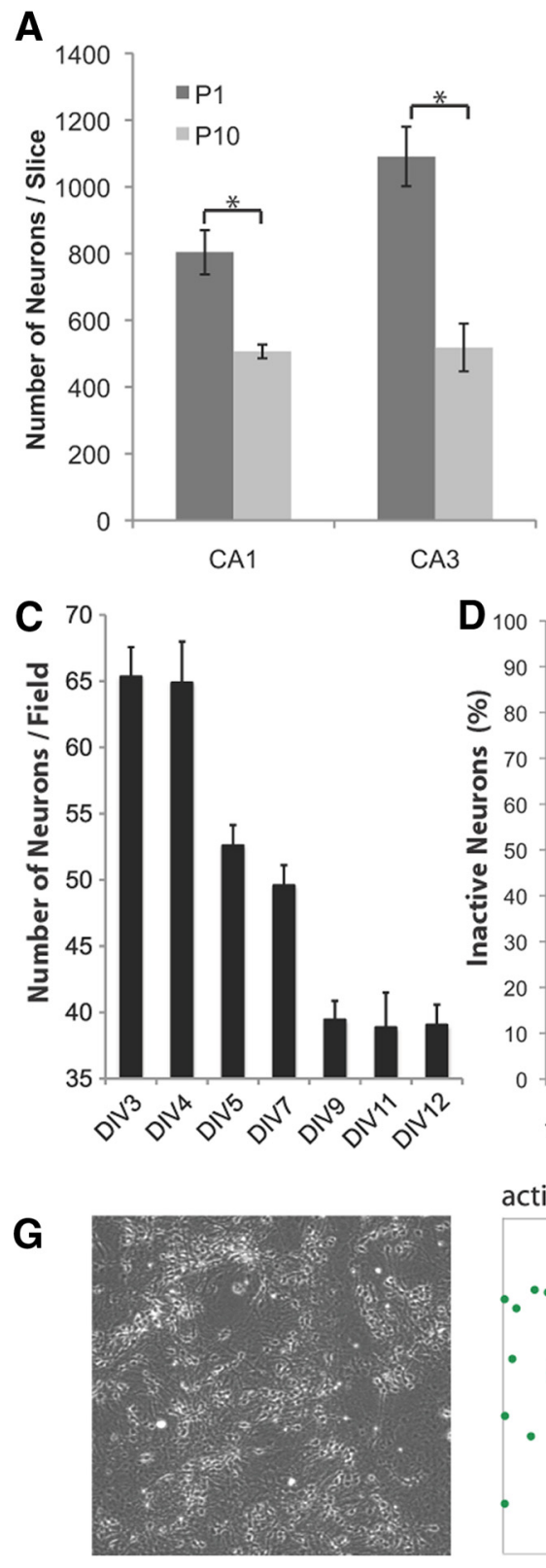
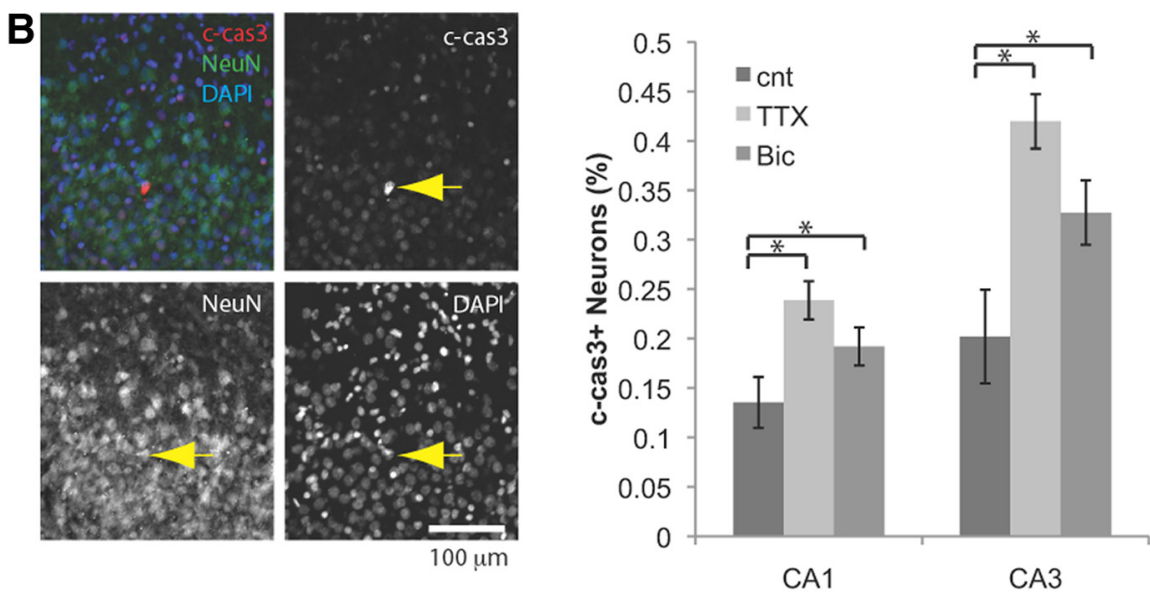

E 1
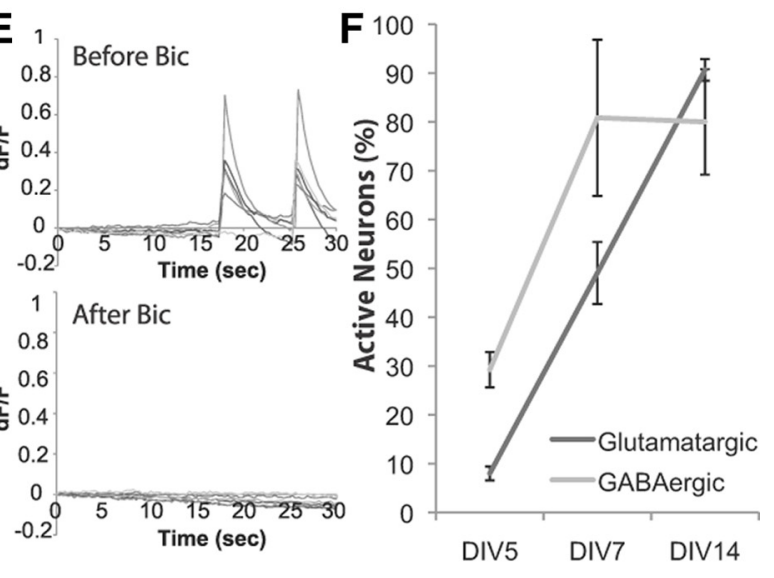
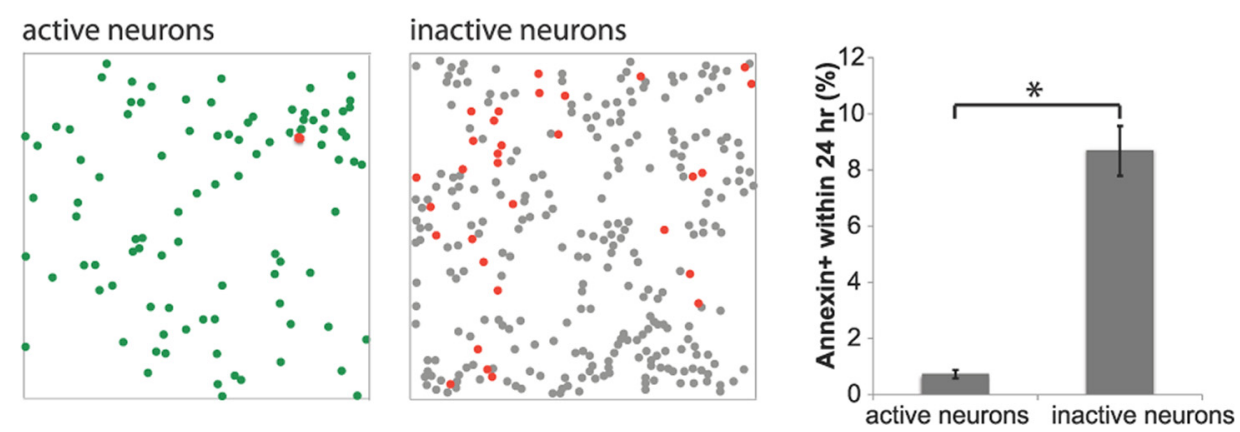

Figure 1. Spontaneous activity is involved in survival. $A$, In vivo, numbers of hippocampal neurons decrease during the postnatal period. Mean numbers of NeuN ${ }^{+}$cells in $C A 1$ and $C A 3$ cell layer are compared between P1 and P10 $(n=6)$. B. Apoptotic neurons were analyzed by immunostaining of c-cas3 and a neuronal marker, NeuN (blue, DAPl; green, NeuN; red, c-cas3). Inhibiting spontaneous activity increased death. Either $0.3 \mu \mathrm{l}$ of $30 \mu \mathrm{m} \mathrm{TTX}$ or $1 \mathrm{~mm}$ bicuculline (Bic) was injected at P2. cnt, Control. c-cas $3^{+}$neurons were analyzed at P3 ( $n=8$ ). ${ }^{*} p<0.05$ (one-way ANOVA). C, The neuronal number declined between DIV4 and DIV9 (5-16 cultures). MAP2 ${ }^{+}$cells were counted $(n=8)$. D, Proportion of spontaneously active neurons. Calcium imaging with Fluo-4 AM was used $(n=5)$. $\boldsymbol{E}$, Spontaneous activity was blocked by $30 \mu \mathrm{m}$ bicuculline. $\boldsymbol{F}$, GABAergic neurons became spontaneously active earlier than glutamatergic neurons at DIV5 $(n=4)$. $\boldsymbol{G}$, From left: Phase image of DIV6 culture, location of active neurons, location of inactive neurons (red dots, annexin ${ }^{+}$within $24 \mathrm{~h}$ ), proportion of neurons that became annexin ${ }^{-}$to annexin ${ }^{+}$within $24 \mathrm{~h}$ period after calcium imaging $(n=5)$. ${ }^{*} p<0.05$.

50\% between P1 and P10 (Fig. 1A). Thus, in the hippocampus, developmental death controls number of neurons.

GABA-dependent network activity in a specific period of neonatal hippocampus development has been well defined (Garaschuk et al., 1998; Wakselman et al., 2008), but it is not known whether this activity is linked to neuronal death. To directly test the effect of neuronal activity on survival, we injected antagonists of voltage-dependent sodium channels (TTX) and $\mathrm{GABA}_{\mathrm{A}}$ receptors (bicuculline) to the neonatal hippocampi. By monitoring apoptotic neurons with immunostaining against c-cas3, we found that bilateral injection of TTX or bicuculline to P2 hippocampus promoted neuron death (Fig. 1B), showing that
GABA-dependent neuronal activity regulates neuronal survival in vivo.

We further investigated the relationship between neuronal activity and survival with dissociated hippocampal neurons. Interactions with astrocytes are known to be important for the maturation and survival of neurons (Blondel et al., 2000; Ullian et al., 2004; Elmariah et al., 2005; Nagai et al., 2007). To study neuronal death, we used hippocampal neurons plated onto astrocytes and showed that, in the central region of 3-mm-diameter coverslips, the density of neurons was reproducible and insensitive to changing the medium or adding the solvent DMSO ( $1 \%$ DMSO; $102.5 \pm 4.1 \%$ and $95.3 \pm 4.1 \%$ of control, $n=6$ ). Under 
these conditions, the number of surviving neurons was stable for the first $4 \mathrm{~d}$ but reproducibly decreased between DIV4 and DIV9 before becoming stable once more (Fig. $1 C$ ). Incubation for $2 \mathrm{~d}$ with the antimitotic drug, FUDR, did not affect the neuron number, showing that neurons were not generated from dividing precursors $(80 \mu \mathrm{M}$ FUDR; $108.2 \pm 5.3 \%$ of control, $n=15$ at DIV4). Including a caspase inhibitor $(20 \mu \mathrm{M})$ or transfecting a plasmid encoding the anti-apoptotic protein Bcl-XL effectively reduced death (119.0 \pm $11.3 \%$ and $135.5 \pm 9.4 \%$ of control, $n=4$ ). These results define a specific period when postmitotic neurons undergo spontaneous apoptosis that eliminates $\sim 40 \%$ of total neurons.

To monitor activity in these developing neurons, we used time-lapse imaging following incubation with Fluo-4 AM, a nonfluorescent acetoxymethyl ester that is cleaved inside cells to the green-fluorescent calcium indicator, Fluo-4. These data show that spontaneous calcium activity was first evident in a small proportion of neurons on DIV4-DIV5, but by DIV11-DIV12, almost all neurons exhibited activity (Fig. $1 D$ ). This activity was synchronous throughout the population of neurons (data not shown) and was completely blocked by the $\mathrm{GABA}_{\mathrm{A}}$ antagonist, bicuculline (Fig. $1 E$ ). When this activity first emerged, a larger proportion of the active neurons expressed high levels of the neurotransmitter GABA (Fig. $1 F$ ). These data suggest that synchronous calcium activity develops during the period when some neurons die, and that GABA plays an early role in this process.

Next, we performed live-imaging experiments to determine the correlation between activity and death. Annexin $\mathrm{V}$ binds to negatively charged phospholipids that are normally present on the inner surface of the plasma membrane but exposed on the surface of dying cells (Koopman et al., 1994). Neuronal activity was monitored optically, and then the cell surface expression of annexin V was monitored for the next $24 \mathrm{~h}$. At DIV6, one-third of the neurons showed spontaneous calcium transients. Only $1 \%$ of these active cells became annexin ${ }^{+}$, whereas $>10 \%$ of the inactive neurons became annexin ${ }^{+}$in the next $24 \mathrm{~h}$ (Fig. $1 G$ ). These results show that inactive neurons were 10 times more likely to die than active ones.

\section{BDNF facilitates activity while promoting survival}

Simultaneous whole-cell recording and calcium imaging have shown that calcium transients [also known as early network oscillations (ENOs)] are associated with action potentials (APs) in hippocampal slices (Garaschuk et al., 1998). In dissociated hippocampal neurons, we found that ENOs were also associated with APs when they become spontaneously active (Fig. 2A). The frequency of these GABA-dependent ENOs increased following application of BDNF (Fig. $2 A$ ). This effect of BDNF was observed only during the death period (DIV7, $188 \pm 17.7 \%, n=6$; DIV11, $108 \pm 17.5 \%$ of control, $n=4)$.

At DIV7, BDNF acutely recruited inactive cells into the active population (Fig. $2 \mathrm{~B}$ ). Treatment with BDNF increased the number of spontaneously active neurons by $20.4 \pm 6.4 \%$ (20\% of inactive neurons are recruited). At DIV5, GABAergic neurons were preferentially activated by BDNF (Fig. 2C). The calcium transients in both previously active neurons and BDNF-recruited neurons were blocked entirely by bicuculline (data not shown). These observations show that BDNF acutely recruits inactive cells into the active population and that GABAergic cells are initially more likely to be activated.

To determine whether exposure to BDNF leads to a long-term change in the proportion of active neurons, we measured neuronal activity by Fluo-4 AM imaging $24 \mathrm{~h}$ after treatment with BDNF. BDNF treatment increased the proportion of active neu- rons more than threefold, and this treatment reduced the number of annexin $\mathrm{V}^{+}$neurons by fivefold (Fig. 2D). These results suggest that BDNF has a long-term effect on neuronal activity and survival.

\section{BDNF fails to promote survival of neurons in the absence of spontaneous activity}

Our results show (1) that inactive neurons are likely to become annexin $^{+}$and (2) that BDNF rapidly promotes activity and reduces the number of annexin ${ }^{+}$neurons. Different models could explain these observations. One possibility is that BDNF supported neuronal survival by promoting activity. Alternatively, there may be two distinct populations of neurons; one that dies and another that shows altered activity in response to BDNF. Therefore, we tested whether BDNF required activity to exert its survival effect. Treatment with BDNF from DIV5 to DIV7 resulted in a significant increase in neuron number (Fig. 3). This effect was abolished in the presence of activity blockade by bicuculline (Fig. 3). This result shows directly that exogenous BDNF requires activity to support neuronal survival.

\section{L-type channels are critical for calcium activity, and activate Akt}

Our calcium-imaging data suggested that the survival effects of BDNF may be mediated through a calcium-dependent system. Nifedipine, the L-type calcium channel antagonist, completely blocked spontaneous ENOs (Fig. 4A). Blocking L-type channels also reduced neuron numbers (Fig. $4 B$ ), suggesting that L-type calcium channels are involved in survival. BDNF did not increase the number of surviving neurons in the presence of nifedipine (Fig. $4 B$ ). These results show that BDNF requires both $\mathrm{GABA}_{\mathrm{A}}$ receptors and the depolarization mediated by L-type calcium channels to support neuronal survival.

Cell survival responses in many systems are controlled by a rapid activation of the phosphoinositol kinase (PI3K) and recruitment of the serine-threonine kinase Akt to the cell surface (Toker and Newton, 2000; Jacinto et al., 2006). Treating hippocampal neurons with GABA induced the phosphorylation of Ser-473 Akt, which can be blocked by LY294002, an inhibitor for PI3K (Fig. 4C). The phosphorylation of Akt was impaired by bicuculline, and when extracellular calcium was depleted with EGTA, or L-type channels were inhibited by nifedipine, GABA did not cause Akt phosphorylation (Fig. 4C). In contrast, the NMDA receptor antagonist APV did not block Akt phosphorylation (Fig. 4C). These results show that depolarization drives L-type channels to regulate the survival of hippocampal neurons, and suggest that this effect may be mediated by the activation of Akt.

\section{Neurotrophins initiate Akt activation that is maintained by L-type channels}

To directly determine how activity is involved in neurotrophininduced cell signaling, we first monitored activation of the tyrosine kinase receptor Trk in response to BDNF and NT3. Trk phosphorylation endured for $<1 \mathrm{~h}$ in the continued presence of these ligands (Fig. 5A). Preincubation with antibodies against TrkB and TrkC, which block receptor-ligand interaction, blocked tyrosine phosphorylation of the receptors (Fig. 5A). EGTA and bicuculline treatment did not block tyrosine phosphorylation of Trk receptors (Fig. 5A).

In contrast to the short-lasting activation of Trk, treatment with neurotrophins caused activation of Akt for $4 \mathrm{~h}$ (Fig. 5A). Preincubation with anti-TrkB and anti-TrkC blocked Akt activa- 
A DIV7

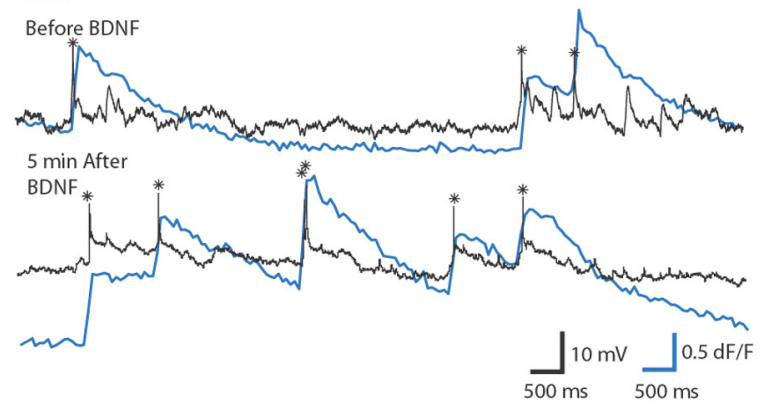

B
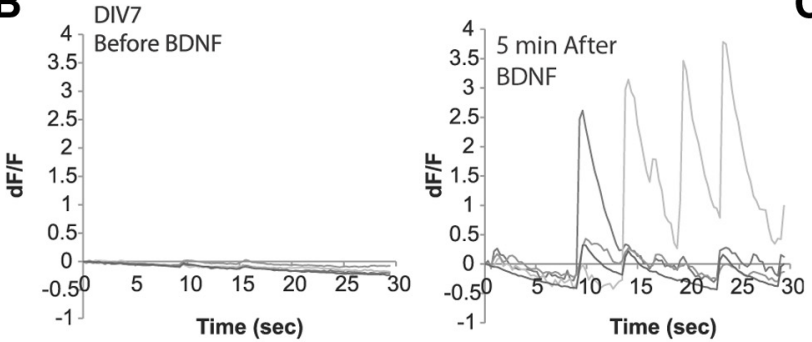

D DI

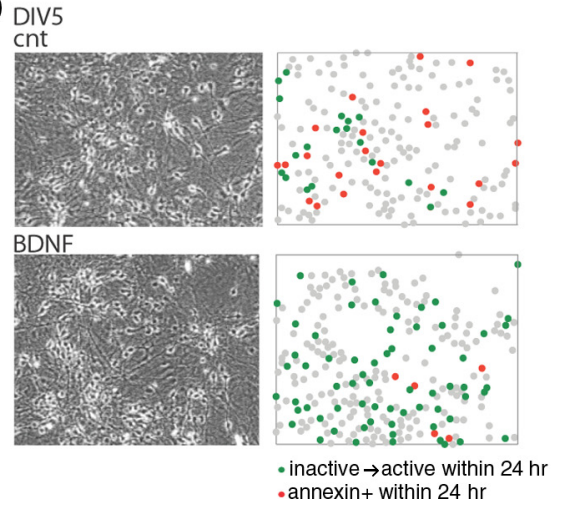

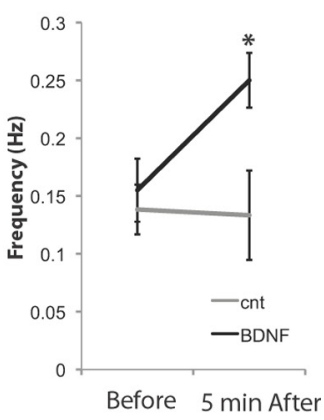

C

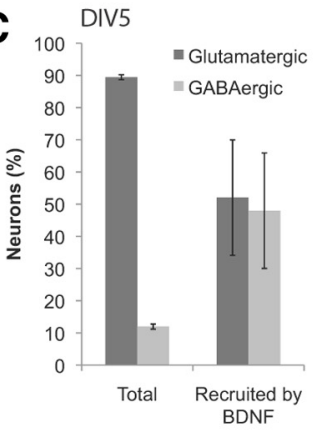

Figure 2. BDNF promotes spontaneous activity and survival. $A$, Left, Calcium signal (blue line) and intracellular recording (black line, action potentials marked with asterisks) show increased activity $5 \mathrm{~min}$ after application of $10 \mathrm{ng} / \mathrm{ml}$ BDNF. Right, Frequency of calcium activity is enhanced by $10 \mathrm{ng} / \mathrm{ml} \mathrm{BDNF}$ in $5 \mathrm{~min}(n=6)$. $B$, Example of inactive neurons (DIV7) becoming active $5 \mathrm{~min}$ after application of $10 \mathrm{ng} / \mathrm{mI} \mathrm{BDNF.} \mathrm{C,} \mathrm{GABAergic} \mathrm{neurons} \mathrm{were} \mathrm{preferentially} \mathrm{recruited} \mathrm{by} \mathrm{BDNF} \mathrm{at} \mathrm{DIV5}(n=7)$. D, BDNF promoted spontaneous activity while suppressing apoptosis. Calcium imaging with Fluo-4 AM was performed at DIV5, and then the cultures were incubated with or without $10 \mathrm{ng} / \mathrm{mI}$ BDNF for $24 \mathrm{~h}$, before the second calcium imaging was performed at DIV6 $(n=5)$. cnt, Control. ${ }^{*} p<0.05$.
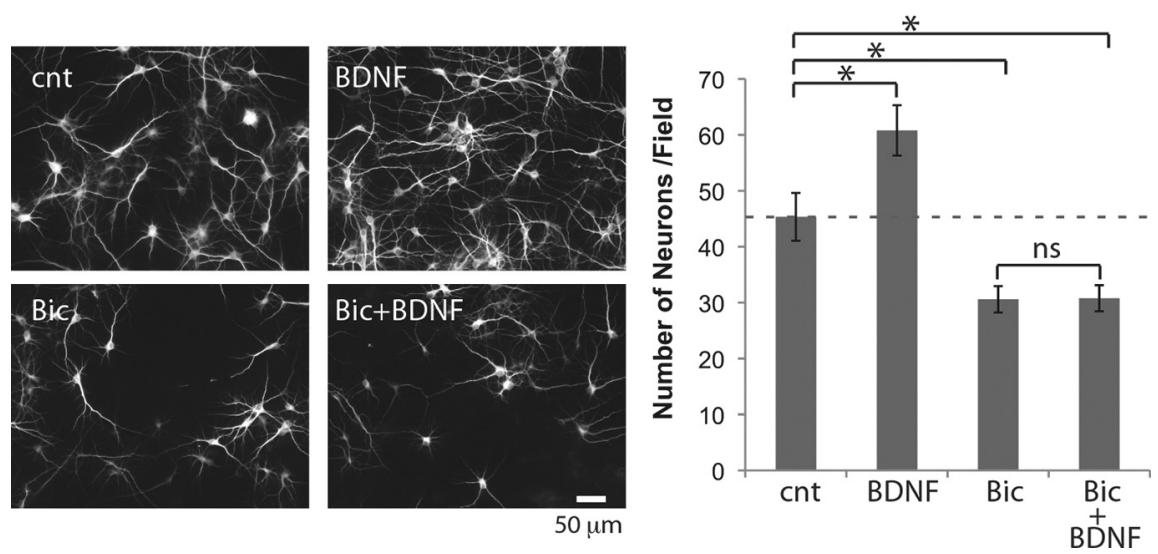

Figure 3. BDNF fails to rescue neurons without spontaneous activity. Left, MAP2 immunostaining. Right, Numbers of neurons $(n=7)$. Neurons were treated with $10 \mathrm{ng} / \mathrm{ml} \mathrm{BDNF}$ and/or $30 \mu \mathrm{m}$ bicuculline (Bic) from DIV5 to DIV7. * $p<0.05$ (one-way ANOVA); ns, not significant; cnt, control.

tion (Fig. 5A). Buffering external calcium with EGTA, blocking $\mathrm{GABA}_{\mathrm{A}}$ receptors or L-type channels, permitted Akt phosphorylation for $1 \mathrm{~h}$ but caused premature downregulation of Akt phosphorylation (Fig. 5A). These data suggest that Akt activation is initiated by Trk activation, but is sustained by activity-driven calcium influx that requires $\mathrm{GABA}_{\mathrm{A}}$ and L-type channels.

\section{Akt is necessary and sufficient for survival}

To determine whether Akt activation is required for neurotrophin survival signaling, neurons were treated with neurotrophins in the presence of LY294002, a drug that is widely used as a selective inhibitor of PI3K. Incubation with BDNF promoted survival, and the addition of NT3 did not enhance this effect (Fig. 5B). Incubation with anti-TrkB and anti-TrkC, on the other hand, reduced the number of surviving neurons below control levels, suggesting a role for endogenous neurotrophins (Fig. 5B). In the presence of LY294002, the survival effect of neurotrophins was blocked, leading to numbers of surviving neurons similar to those observed when neurotrophin signaling was blocked (Fig. 5B). This result suggests that activation of Akt is necessary for neurotrophin-dependent survival.

Akt activation promotes its localization to the membrane, and when Akt is tagged with a myristoylation site, it becomes constitutively active (Kohn et al., 1996). To test whether Akt activation is sufficient for survival, we overexpressed myristoylated Akt in neurons. When neurons were transfected with a control plasmid expressing only green fluorescent protein (GFP), the decline in numbers of transfected neurons from DIV5 to DIV7 was exacerbated by nifedipine (Fig. 5B). However, when neurons were cotransfected with myristoylated Akt, the numbers of neurons did not change over time, and nifedipine had no effect on the number (Fig. 5C). These results suggest that constitutively active Akt is sufficient to suppress neuronal death.

\section{Integrin $\beta 1$ signaling is necessary for neurotrophin-dependent survival} Akt has two phosphorylation targets for PI3K at Thr-308 and Ser-473 that mediate distinct downstream effects in survival and growth signaling (Jacinto et al., 2006). We found that depolarizing hippocampal neurons by applying elevated $\mathrm{K}^{+}$induced the phosphorylation of both sites, and these phosphorylation events were both 
attenuated by nifedipine (Fig. 6A). Because the extracellular matrix is known to play an important role in cell survival, and laminin acting through integrin receptors is known to influence the survival of hippocampal neurons (Gary et al., 2003), we explored the role of integrin in this survival pathway.

Echistatin, a disintegrin derived from snake venom that blocks specifically $\beta 1 /$ $\beta 3$-containing integrins (Pfaff et al., 1994), and a function-blocking antibody against the $\beta 1$ subunit of integrin (Mendrick and Kelly, 1993), specifically impaired phosphorylation of Ser-473 (Fig. $6 A)$. On the other hand, a functionblocking antibody against integrin $\beta 3$ (Helfrich et al., 1992) had no effect on either phosphorylation site (Fig. 6A). These results suggest that L-type channel-induced phosphorylation of Akt at Ser-473 requires integrin $\beta 1$ signaling.

If integrin $\beta 1$ is required for L-type channel-induced Akt activation, the sustained Akt activation by neurotrophins should also be integrin $\beta 1$ dependent. Neither the sensitivity of Trk activation nor the duration of Trk activation was affected by anti-integrin $\beta 1$ antibody (Fig. 6B). While initial transient activation of Akt was intact in the presence of integrin $\beta 1$ blockade, the sustained Akt activation was impaired (Fig. $6 B$ ). Inhibition of integrin $\beta 3$, on the other hand, had no effect on Akt activation (Fig. $6 B)$. Although it has been reported that neurotrophins directly bind to integrin $\alpha 9 \beta 1$ (Staniszewska et al., 2008), the function blocking anti-integrin $\beta 1$ antibody did not block the transient Akt activation by neurotrophins, which was completely attenuated by anti-TrkB and anti-TrkC antibodies (Fig. 6B). Therefore, it is likely that the transient Akt activation was triggered by Trk receptor activation. These results show that, independent of the initial activation mechanism, integrin $\beta 1$ is required for sustained Akt activation on Ser- 473 that is triggered by neurotrophins.

If integrin $\beta 1$ is required for neurotrophin-dependent survival of neurons, inhibition of integrin $\beta 1$ should attenuate the survival effect of neurotrophins. Indeed, we found that in the presence of echistatin or anti-integrin $\beta 1$ antibody, the number of surviving neurons was decreased, and neurotrophins failed to promote neuronal survival (Fig. 6C). Antiintegrin $\beta 3$ antibody did not affect the number of surviving neurons (105.7 \pm $4.2 \%$ of control, $n=6$ ). When neurons were cotransfected with GFP and myristoylated Akt, the number of transfected neurons did not change by the anti-integrin $\beta 1$
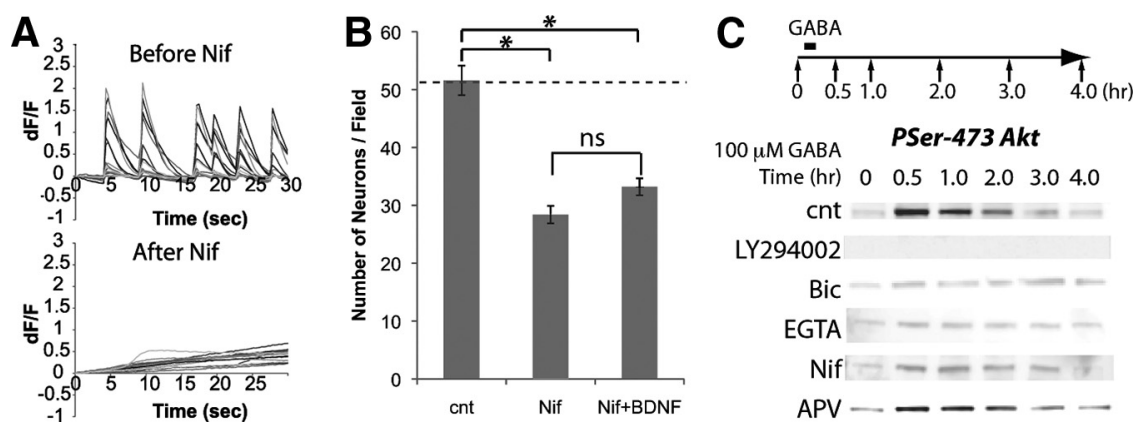

Figure 4. L-type channels are required for spontaneous activity and survival. $\boldsymbol{A}$, Calcium events were attenuated by nifedipine (Nif). $\boldsymbol{B}$, Neuronal death was induced by nifedipine $(n=5)$. C, Activation of L-type channels by depolarization (100 $\mu$ M GABA for $5 \mathrm{~min}$ ) induced Akt phosphorylation. Concentrations of $30 \mu \mathrm{m}$ bicuculline, $5 \mathrm{~mm}$ EGTA, $100 \mu \mathrm{m} \mathrm{APV}, 10 \mu \mathrm{m}$ nifedipine, and $10 \mu \mathrm{m}$ LY294002 were used. cnt, Control. * $p<0.05$ (one-way ANOVA).
A

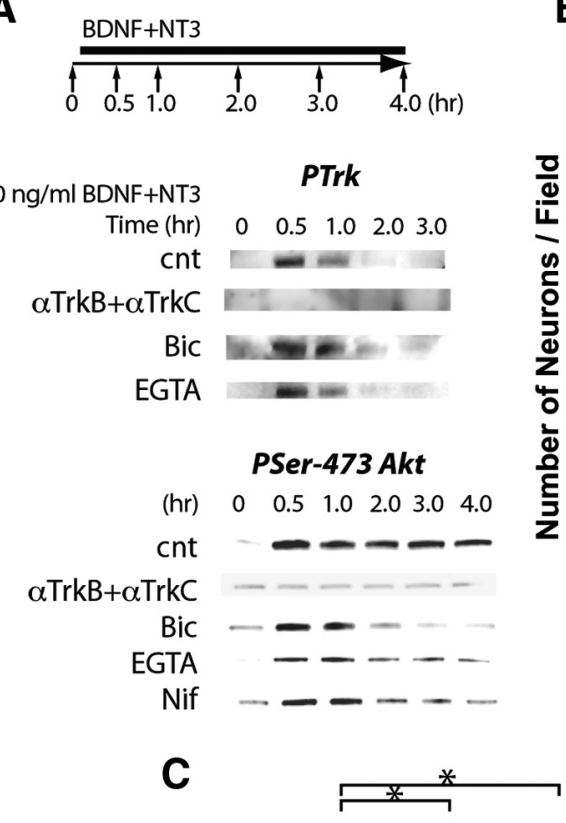

B

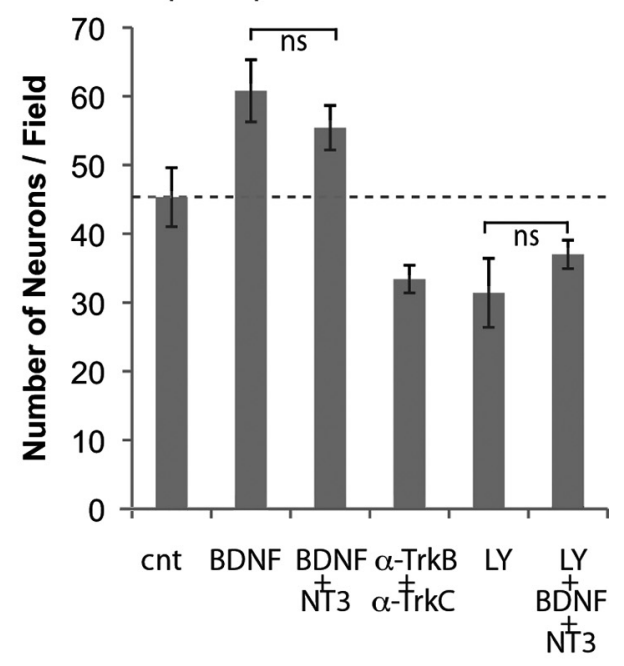

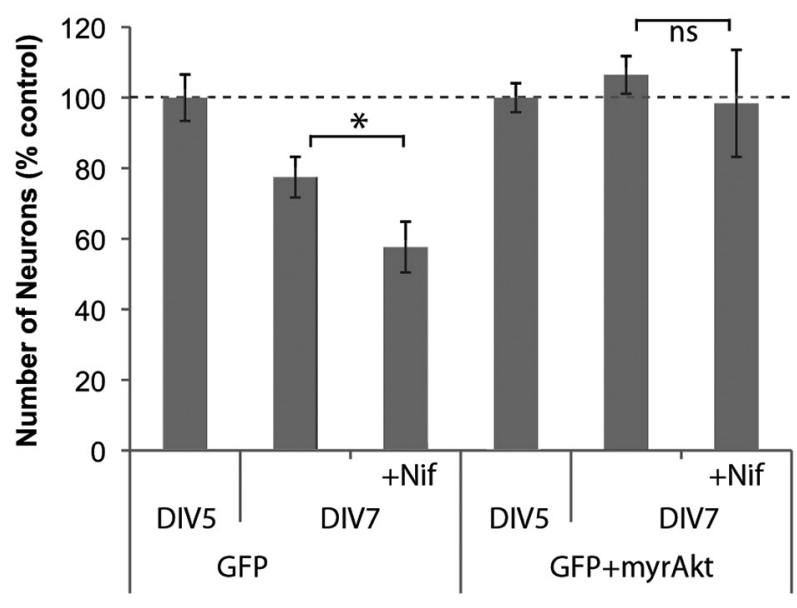

Figure 5. Neurotrophins initiate Akt activation that is maintained by L-type channels. $A, B D N F$ and NT3 $(10 \mathrm{ng} / \mathrm{ml})$ induced phosphorylation of Trk, and sustained phosphorylation of Ser-473 Akt; $50 \mu \mathrm{g} / \mathrm{ml}$ anti-TrkB and anti-TrkC, $30 \mu \mathrm{M}$ bicuculline (Bic), $5 \mathrm{~mm}$ EGTA, and $10 \mu \mathrm{m}$ nifedipine were used. $\boldsymbol{B}$, Neurons were treated from DIV5 to DIV7 $(n=7) ; 10 \mathrm{ng} / \mathrm{ml}$ BDNF and NT3, $50 \mu \mathrm{g} / \mathrm{ml}$ anti-TrkB and anti-TrkC, and $10 \mu \mathrm{m}$ LY294002 (LY) were used. C, Overexpression of constitutively active Akt by transfection of a plasmid encoding Akt CDNA with a myristoylation signal. Transfection was performed at DIV4, and neurons were treated with $10 \mu$ m nifedipine from DIV5 to DIV7 ( $n=5$ ). cnt, Control. ${ }^{*} p<0.05$ (one-way ANOVA). 
A
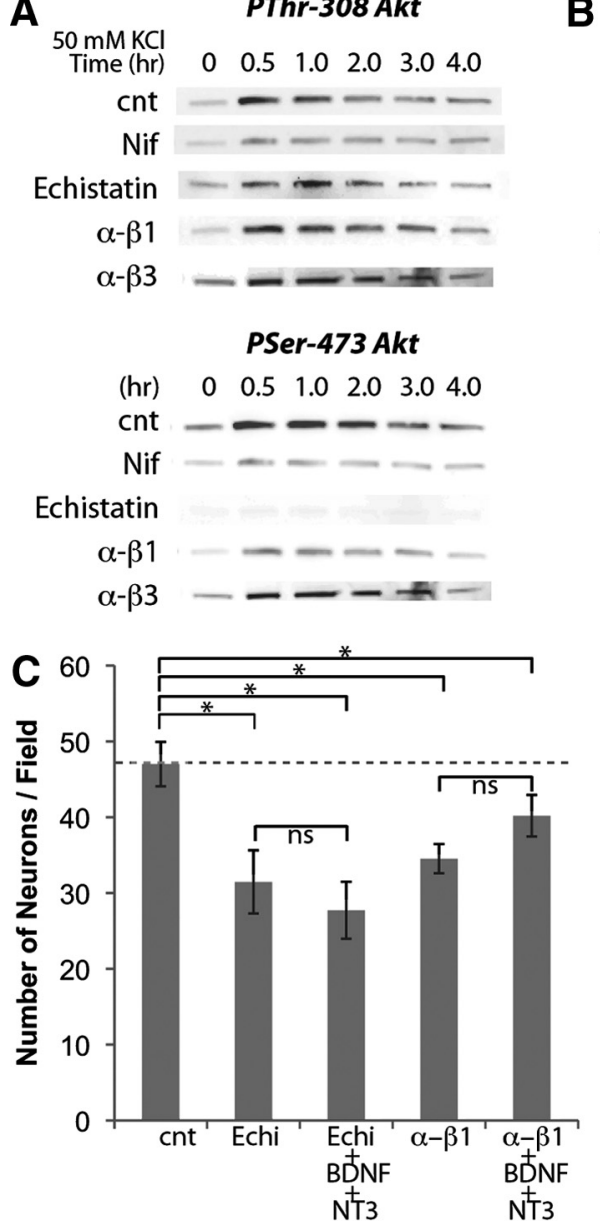

D

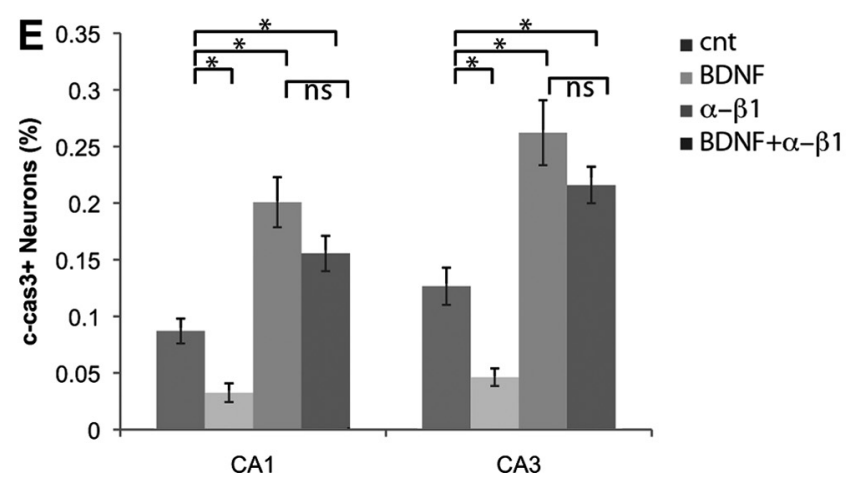

Figure 6. L-type channels cooperate with integrin $\beta 1$ to activate Akt and promote survival. $A$, Activation of Akt by depolarization with $50 \mathrm{~mm} \mathrm{KCl}$ for 5 min required L-type channels. Phosphorylation of Ser-473 but not Thr-308 was impaired by echistatin or anti-integrin $\beta 1$ antibody. $\boldsymbol{B}$, Neurotrophin-induced phosphorylation of Trk receptors was not affected by anti-integrin $\beta 1$ antibody, but the sustained Akt activation was impaired. $C$, Incubation with echistatin or anti-integrin $\beta 1$ antibody reduced the number of surviving neurons and attenuated the survival effect of neurotrophins. Treatment was from DIV5 to DIV7 $(n=6)$. D, Cotransfection of GFP and myristoylated Akt blocked the effect of antiintegrin $\beta 1$ antibody on neuronal survival. Transfection was at DIV4 and treatment from DIV5 to DIV7 $(n=6) ; 10 \mu \mathrm{M}$ nifedipine (Nif), $0.1 \mu \mathrm{m}$ echistatin, $50 \mu \mathrm{g} / \mathrm{ml}$ anti-integrin $\beta 1$ and anti-integrin $\beta 3$ antibodies, and $10 \mathrm{ng} / \mathrm{ml}$ BDNF and NT3 were used. $\boldsymbol{E}$, In vivo delivery of BDNF reduced apoptosis while anti- $\beta 1$ antibody increased. BDNF failed to reduce apoptosis when integrin $\beta 1$ was inhibited; $0.3 \mu$ of $0.5 \mathrm{mg} / \mathrm{ml}$ anti- $\beta 1,50 \mu \mathrm{g} / \mathrm{ml} \mathrm{BDNF}$ were injected at P2, and c-cas $3^{+}$ neurons were analyzed at P4 $(n=6)$. cnt, Control. ${ }^{*} p<0.05$ (one-way ANOVA).

antibody (Fig. 6D), confirming that sustained Akt activation is sufficient to rescue neurons from integrin $\beta 1$ blockade. These results suggest that the survival effects induced by neurotrophins require integrin $\beta 1$ signaling.
Manipulations in vivo confirm the survival pathway is conserved

Molecules involved in the survival of hippocampal neurons during the death period play important roles in earlier stages of development, and mice lacking neurotrophin or integrin receptors have been shown not to survive through the period when hippocampal neurons die (Stephens et al., 1995; Silos-Santiago et al., 1997). To achieve precisely timed manipulations of survival signals, we made microinjections into the neonatal hippocampus. When BDNF was injected into P2 hippocampus, the number of $\mathrm{c}$-cas $3^{+}$neurons in both $\mathrm{CA} 1$ and CA3 regions was reduced (Fig. $6 E)$. In contrast, injection of the antiintegrin $\beta 1$ antibody led to increased numbers of $\mathrm{c}$-cas $3^{+}$neurons (Fig. $6 E$ ). As with in vitro experiments, the survival effect of BDNF was not observed in the presence of anti-integrin $\beta 1$ antibody (Fig. 6E). These results suggest that neurotrophins promote survival through an integrin-dependent mechanism in vivo.

\section{Discussion}

The goal of this study was to understand whether neurotrophins control neuronal number during the specific stage of postnatal development when spontaneous neuron loss occurs. As summarized in Figure 7, we first found that neuronal survival in the postnatal hippocampus required spontaneous GABA-dependent activity. We then used in vitro systems to show that BDNF promoted GABAdependent network activity while suppressing apoptosis (Fig. 7A). Transient Trk receptor activation by neurotrophins triggered Akt activation that was maintained by calcium influx through L-type channels and also required signals from integrin receptors (Fig. 7B). Finally, experiments performed in vivo demonstrated that neurotrophins regulated neuron death through an integrin-dependent mechanism. These results support a new view of the survival mechanisms activated by neurotrophins.

Since apoptosis was first reported in the neonatal hippocampus (Ferrer et al., 1994), this developmental death has been confirmed by other groups (White et al., 1998; Wakselman et al., 2008). Our results, obtained in vivo and in vitro, are consistent with these findings: by analyzing numbers of $\mathrm{c}$-cas $3^{+}$neurons, we confirmed the extent of apoptosis reported previously. Further, consistent with previous results (Ferrer et al., 1994), we did not observe apoptotic neurons after P10 (data not shown). Together, these results establish that developmental death eliminates a large proportion of 
neurons from the hippocampus, indicating that this process plays an important role in controlling numbers of surviving neurons in this brain structure.

In contrast to the dramatic loss of neurons observed in the PNS, genetic deletion of neurotrophins and their receptors have little effect on neuron number in the CNS, including hippocampus (Jones et al., 1994; Minichiello and Klein, 1996; Alcántara et al., 1997; Rauskolb et al., 2010). These studies have led to the suggestion that neurotrophins may not be involved in the survival of CNS neurons. However, our results obtained in vivo and in vitro demonstrate that neurotrophins are required for the survival of hippocampal neurons and that neurotrophins support neuronal survival by promoting network activity. In pathological neuronal loss of CNS neurons, neurotrophins may play a major neuroprotective role (Nagahara et al., 2009; Nikolaev et al., 2009). Whether or not the survival mechanism presented here is conserved in neurodegenerative diseases remains to be elucidated.

Depolarizing GABA during development promotes neuronal differentiation through the action of BDNF (Marty et al., 1996). Transcription and release of BDNF is stimulated by GABA (Berninger et al., 1995; Kuczewski et al., 2008). These results are consistent with the commonly held model that neural activity causes neurotrophin release and this promotes survival. Our data show that neurotrophins cannot exert their effects on survival in the absence of neuroactivity, and thus assign a central role for activity in neurotrophin-mediated survival. We report two effects of BDNF on neuronal activity, an increase in the frequency of calcium oscillations (ENOs) and the recruitment of silent neurons to active networks. Precise mechanisms for these effects remain to be elucidated. One possibility is that BDNF alters excitability of the neurons. However, young hippocampal neurons do not show changes in either $\mathrm{K}^{+}$- or $\mathrm{Na}^{+}$currents after BDNF treatment (Li et al., 1998). Another possibility is that BDNF alters synaptic properties (Li et al., 1998; Wardle and Poo, 2003). The neurotrophic effects of BDNF emphasize the importance of a rapid change in the activity state of hippocampal neurons at this stage of their maturation.

We show that the serine-threonine kinase Akt is necessary and sufficient for neuronal survival. Akt activation by receptor tyrosine kinases is generally rapid (Franke et al., 1995; Yoshizaki et al., 2007), but this is sufficient to induce survival responses (Androutsellis-Theotokis et al., 2006). Our data show that the kinetics of Akt signaling is longer-lasting in neurons than in other cell types, and the long-lasting Akt-activation is required for neuronal survival. We found that phosphorylation of Ser-473 Akt induced by calcium influx through L-type channels specifically required integrin $\beta 1$. The mechanisms of Akt activation have
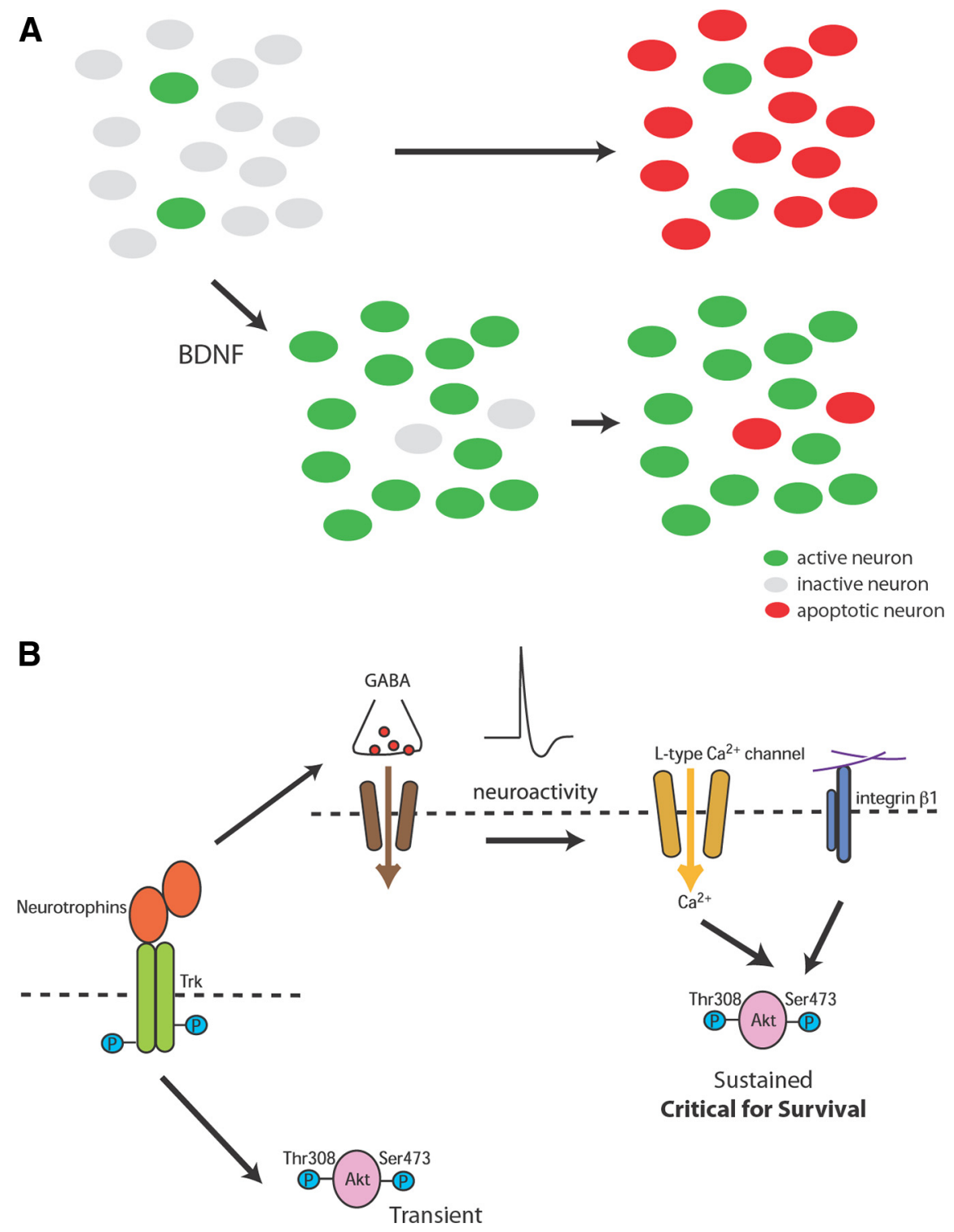

Figure 7. Schematic drawings of how neurotrophins promote survival of neurons in neonate. $A$, During the neonatal period when spontaneous network activity is developing, BDNF promotes spontaneous activity while suppressing the apoptosis. $\boldsymbol{B}$ Molecular mechanism by which neurotrophins exert survival effect via promoting spontaneous activity. Activation of Trk receptor triggers Akt activation that is maintained by spontaneous activity-driven calcium influx through L-type channels. The sustained Akt, which requires signal from integrin $\beta 1$ signaling, is necessary and sufficient for neurotrophin-dependent survival.

been intensively studied in the context of cancer biology, where a kinase cascade activated by tyrosine kinase leads to phosphorylation of Akt at Thr-308. This event is required for subsequent phosphorylation of Akt at Ser-473 (Balendran et al., 1999; Toker and Newton, 2000). The mTOR complex 2 (mTORC2), a signaling complex related to the well defined, rapamycin-sensitive mTORC1, phosphorylates Akt at Ser-473 and plays a specific role in cell survival (Jacinto et al., 2006). Our data suggest that both phosphorylation events are required for neuronal survival and reveal a novel mechanism, assigning a central role to neuronal activity in activating this process.

Our study revealed a specific role for the integrin $\beta 1$ subunit in the survival signaling of neonatal neurons in hippocampus. The ligand that activates integrin $\beta 1$ to sustain Akt phosphorylation remains unknown. One candidate ligand is laminin, an extracellular-matrix protein that binds to and is expressed by neonatal neurons (Hynes, 2002; Sharif et al., 2004). Alternatively, 
the unknown ligand may be provided by non-neuronal cells. Contact with astrocytes, for example, facilitates synapse formation in young hippocampal neurons via signaling from integrin $\beta 1$ (Hama et al., 2004). Further investigations of the spatial and temporal distribution of integrin $\beta 1$ and its ligands may help to reveal mechanisms by which neurocircuitry is sculpted through neuronal death.

Our data show that it is important for a neuron to participate in an active network to survive the neonatal period, and that depolarizing GABA plays a key role in this mechanism. Depolarizing GABA is critical for the spontaneous network activity that is believed to establish the circuitry of the neonatal hippocampus (Ben-Ari et al., 1989). An appropriate balance between excitatory and inhibitory inputs is critical for normal adult brain function. Our results suggest that neurotrophin-mediated activity may ensure that neurons only survive when they are appropriately linked to a functional network with strong GABAergic input.

\section{References}

Alcántara S, Frisén J, del Río JA, Soriano E, Barbacid M, Silos-Santiago I (1997) TrkB signaling is required for postnatal survival of CNS neurons and protects hippocampal and motor neurons from axotomy-induced cell death. J Neurosci 17:3623-3633.

Androutsellis-Theotokis A, Leker RR, Soldner F, Hoeppner DJ, Ravin R, Poser SW, Rueger MA, Bae SK, Kittappa R, McKay RD (2006) Notch signalling regulates stem cell numbers in vitro and in vivo. Nature 442:823-826.

Balendran A, Casamayor A, Deak M, Paterson A, Gaffney P, Currie R, Downes CP, Alessi DR (1999) PDK1 acquires PDK2 activity in the presence of a synthetic peptide derived from the carboxyl terminus of PRK2. Curr Biol 9:393-404.

Barde YA (1994) Neurotrophins: a family of proteins supporting the survival of neurons. Prog Clin Biol Res 390:45-56.

Ben-Ari Y, Cherubini E, Corradetti R, Gaiarsa JL (1989) Giant synaptic potentials in immature rat CA3 hippocampal neurones. J Physiol 416:303-325.

Ben-Ari Y, Khazipov R, Leinekugel X, Caillard O, Gaiarsa JL (1997) GABAA, NMDA and AMPA receptors: a developmentally regulated 'ménage à trois'. Trends Neurosci 20:523-529.

Berninger B, Marty S, Zafra F, da Penha Berzaghi M, Thoenen H, Lindholm D (1995) GABAergic stimulation switches from enhancing to repressing BDNF expression in rat hippocampal neurons during maturation in vitro. Development 121:2327-2335.

Bibel M, Barde YA (2000) Neurotrophins: key regulators of cell fate and cell shape in the vertebrate nervous system. Genes Dev 14:2919-2937.

Blondel O, Collin C, McCarran WJ, Zhu S, Zamostiano R, Gozes I, Brenneman DE, McKay RD (2000) A glia-derived signal regulating neuronal differentiation. J Neurosci 20:8012-8020.

Chavis P, Westbrook G (2001) Integrins mediate functional pre- and postsynaptic maturation at a hippocampal synapse. Nature 411:317-321.

Cooke SF, Bliss TV (2006) Plasticity in the human central nervous system. Brain 129:1659-1673.

Cunningham MG, McKay RD (1993) A hypothermic miniaturized stereotaxic instrument for surgery in newborn rats. J Neurosci Methods 47:105-114.

Elmariah SB, Oh EJ, Hughes EG, Balice-Gordon RJ (2005) Astrocytes regulate inhibitory synapse formation via Trk-mediated modulation of postsynaptic GABAA receptors. J Neurosci 25:3638-3650.

Ferrer I, Tortosa A, Blanco R, Martín F, Serrano T, Planas A, Macaya A (1994) Naturally occurring cell death in the developing cerebral cortex of the rat. Evidence of apoptosis-associated internucleosomal DNA fragmentation. Neurosci Lett 182:77-79.

Franke TF, Yang SI, Chan TO, Datta K, Kazlauskas A, Morrison DK, Kaplan DR, Tsichlis PN (1995) The protein kinase encoded by the Akt protooncogene is a target of the PDGF-activated phosphatidylinositol 3-kinase. Cell 81:727-736.

Garaschuk O, Hanse E, Konnerth A (1998) Developmental profile and synaptic origin of early network oscillations in the CA1 region of rat neonatal hippocampus. J Physiol 507:219-236.

Gary DS, Milhavet O, Camandola S, Mattson MP (2003) Essential role for integrin linked kinase in Akt-mediated integrin survival signaling in hippocampal neurons. J Neurochem 84:878-890.

Gould E, Woolley CS, McEwen BS (1991) Naturally occurring cell death in the developing dentate gyrus of the rat. J Comp Neurol 304:408-418.

Hama H, Hara C, Yamaguchi K, Miyawaki A (2004) PKC signaling mediates global enhancement of excitatory synaptogenesis in neurons triggered by local contact with astrocytes. Neuron 41:405-415.

Helfrich MH, Nesbitt SA, Dorey EL, Horton MA (1992) Rat osteoclasts adhere to a wide range of RGD (Arg-Gly-Asp) peptide-containing proteins, including the bone sialoproteins and fibronectin, via a beta 3 integrin. J Bone Miner Res 7:335-343.

Hynes RO (2002) Integrins: bidirectional, allosteric signaling machines. Cell 110:673-687.

Jacinto E, Facchinetti V, Liu D, Soto N, Wei S, Jung SY, Huang Q, Qin J, Su B (2006) SIN1/MIP1 maintains rictor-mTOR complex integrity and regulates Akt phosphorylation and substrate specificity. Cell 127:125-137.

Jones KR, Fariñas I, Backus C, Reichardt LF (1994) Targeted disruption of the BDNF gene perturbs brain and sensory neuron development but not motor neuron development. Cell 76:989-999.

Kohn AD, Takeuchi F, Roth RA (1996) Akt, a pleckstrin homology domain containing kinase, is activated primarily by phosphorylation. J Biol Chem 271:21920-21926.

Koopman G, Reutelingsperger CP, Kuijten GA, Keehnen RM, Pals ST, van Oers MH (1994) Annexin V for flow cytometric detection of phosphatidylserine expression on B cells undergoing apoptosis. Blood 84:1415-1420.

Kuczewski N, Porcher C, Ferrand N, Fiorentino H, Pellegrino C, Kolarow R, Lessmann V, Medina I, Gaiarsa JL (2008) Backpropagating action potentials trigger dendritic release of BDNF during spontaneous network activity. J Neurosci 28:7013-7023.

Levi-Montalcini R (1987) The nerve growth factor 35 years later. Science 237:1154-1162.

Li YX, Zhang Y, Lester HA, Schuman EM, Davidson N (1998) Enhancement of neurotransmitter release induced by brain-derived neurotrophic factor in cultured hippocampal neurons. J Neurosci 18:10231-10240.

Liu XH, Collier RJ, Youle RJ (2001) Inhibition of axotomy-induced neuronal apoptosis by extracellular delivery of a Bcl-XL fusion protein. J Biol Chem 276:46326-46332.

Marty S, Berninger B, Carroll P, Thoenen H (1996) GABAergic stimulation regulates the phenotype of hippocampal interneurons through the regulation of brain-derived neurotrophic factor. Neuron 16:565-570.

Mendrick DL, Kelly DM (1993) Temporal expression of VLA-2 and modulation of its ligand specificity by rat glomerular epithelial cells in vitro. Lab Invest 69:690-702.

Minichiello L, Klein R (1996) TrkB and TrkC neurotrophin receptors cooperate in promoting survival of hippocampal and cerebellar granule neurons. Genes Dev 10:2849-2858.

Murase S, McKay RD (2006) A specific survival response in dopamine neurons at most risk in Parkinson's disease. J Neurosci 26:9750-9760.

Nagahara AH, Merrill DA, Coppola G, Tsukada S, Schroeder BE, Shaked GM, Wang L, Blesch A, Kim A, Conner JM, Rockenstein E, Chao MV, Koo EH, Geschwind D, Masliah E, Chiba AA, Tuszynski MH (2009) Neuroprotective effects of brain-derived neurotrophic factor in rodent and primate models of Alzheimer's disease. Nat Med 15:331-337.

Nagai M, Re DB, Nagata T, Chalazonitis A, Jessell TM, Wichterle H, Przedborski S (2007) Astrocytes expressing ALS-linked mutated SOD1 release factors selectively toxic to motor neurons. Nat Neurosci 10:615-622.

Nikolaev A, McLaughlin T, O'Leary DD, Tessier-Lavigne M (2009) APP binds DR6 to trigger axon pruning and neuron death via distinct caspases. Nature 457:981-989.

Pfaff M, McLane MA, Beviglia L, Niewiarowski S, Timpl R (1994) Comparison of disintegrins with limited variation in the RGD loop in their binding to purified integrins alpha IIb beta 3 , alpha $\mathrm{V}$ beta 3 and alpha 5 beta 1 and in cell adhesion inhibition. Cell Adhes Commun 2:491-501.

Rauskolb S, Zagrebelsky M, Dreznjak A, Deogracias R, Matsumoto T, Wiese S, Erne B, Sendtner M, Schaeren-Wiemers N, Korte M, Barde YA (2010) Global deprivation of brain-derived neurotrophic factor in the CNS reveals an area-specific requirement for dendritic growth. J Neurosci 30:1739-1749.

Sharif KA, Baker H, Gudas LJ (2004) Differential regulation of laminin b1 transgene expression in the neonatal and adult mouse brain. Neuroscience 126:967-978. 
Silos-Santiago I, Fagan AM, Garber M, Fritzsch B, Barbacid M (1997) Severe sensory deficits but normal CNS development in newborn mice lacking TrkB and TrkC tyrosine protein kinase receptors. Eur J Neurosci 9:2045-2056.

Stanco A, Szekeres C, Patel N, Rao S, Campbell K, Kreidberg JA, Polleux F, Anton ES (2009) Netrin-1-alpha3betal integrin interactions regulate the migration of interneurons through the cortical marginal zone. Proc Natl Acad Sci U S A 106:7595-7600.

Staniszewska I, Sariyer IK, Lecht S, Brown MC, Walsh EM, Tuszynski GP, Safak M, Lazarovici P, Marcinkiewicz C (2008) Integrin alpha9 betal is a receptor for nerve growth factor and other neurotrophins. J Cell Sci 121:504-513.

Stephens LE, Sutherland AE, Klimanskaya IV, Andrieux A, Meneses J, Pedersen RA, Damsky CH (1995) Deletion of beta 1 integrins in mice results in inner cell mass failure and peri-implantation lethality. Genes Dev 9:1883-1895.

Toker A, Newton AC (2000) Cellular signaling: pivoting around PDK-1. Cell 103:185-188.
Ullian EM, Christopherson KS, Barres BA (2004) Role for glia in synaptogenesis. Glia 47:209-216.

Wakselman S, Béchade C, Roumier A, Bernard D, Triller A, Bessis A (2008) Developmental neuronal death in hippocampus requires the microglial CD11b integrin and DAP12 immunoreceptor. J Neurosci 28:8138-8143.

Wardle RA, Poo MM (2003) Brain-derived neurotrophic factor modulation of GABAergic synapses by postsynaptic regulation of chloride transport. J Neurosci 23:8722-8732.

White FA, Keller-Peck CR, Knudson CM, Korsmeyer SJ, Snider WD (1998) Widespread elimination of naturally occurring neuronal death in Baxdeficient mice. J Neurosci 18:1428-1439.

Yoshizaki H, Mochizuki N, Gotoh Y, Matsuda M (2007) Akt-PDK1 complex mediates epidermal growth factor-induced membrane protrusion through Ral activation. Mol Biol Cell 18:119-128.

Zweifel LS, Kuruvilla R, Ginty DD (2005) Functions and mechanisms of retrograde neurotrophin signalling. Nat Rev Neurosci 6:615-625. 